\title{
Play Behavior by a Yellow Monitor, Varanus flavescens (Hardwicke and Gray 1827)
}

Naim Khandakar, Kamrun Nahar Jeny, Shariful Islam, Md. Azizul Hakim, and Iftekharul Amin Pony

Department of Zoology, Jagannath University, Dhaka-1100, Bangladesh (naim.jnu.2014@gmail.com)

Photographs by the senior author.

$\mathrm{P}$ lay is defined as an activity in which an animal engages for pleasure or enjoyment rather than for any serious or practical purpose. Initially, play was thought to be limited to mammals and birds, but efforts to define it more objectively have led to the identification of play in a variety of other taxa (Burghardt 2014) as diverse as reptiles, including monitor lizards (Hill 1946; Kane et al. 2019), turtles (Burghardt et al. 1996; Kramer and Burghardt 1998), and crocodilians (Lazell and Spitzer 1977; Dinets 2015). Herein, we describe presumptive play behavior of a Yellow Monitor (Varanus flavescens) in Bangladesh.

At 1033 h on 8 March 2019, we noticed a Yellow Monitor swimming in a wetland at Mirpara in Dhaka, Bangladesh $\left(23.72735^{\circ} \mathrm{N}, 90.48620^{\circ} \mathrm{E}\right)$. The monitor was swimming in a vertical position, alternately moving forward and backward, between periods during which it floated motionless on the surface. We observed five repetitions of this apparent play behavior in a 30-minute period. These lasted $149,178,94,164$, and 130 seconds, respectively (mean $=143$ sec) and the gaps between each bout lasted 40, 65, 32, and 23 seconds, respectively (mean $=40 \mathrm{sec})$.
Within animal groups, a propensity for play appears to be correlated with brain size (Iwaniuk 2001). Primates display the most play behavior among mammals (Burghardt 2014). This has been linked to their relatively high energy efficiency in dealing with the costs of maintenance and growth (Burghardt 2014; Pontzer et al. 2014), which could provide the excess energy required to facilitate both increased cognitive capacity and play. Monitor lizards, with their high cognitive capacity and problemsolving abilities, energy efficiency, dexterous appendages, and acute vision (Dryden et al. 1990; Cooper et al. 2000; Manrod et al. 2008; Gaalema 2011; Mendyk and Horn 2011), may be regarded in some ways as the squamate equivalent of primates.

\section{Literature Cited}

Burghardt, G.M. 2014. A brief glimpse at the long evolutionary history of play. Animal Behavior and Cognition 1: 90-98.

Burghardt, G.M., B. Ward, and R. Rosscoe1996. Problem of reptile play: Environmental enrichment and play behavior in a captive Nile soft shelled turtle, Trionyx triunguis. Zoo Biology 15: 223-238.

Cooper, T., A. Liew, G. Andrle, E. Cafritz, H. Dallas, T. Niesen, E. Slater, J. Stockert, T. Vold, M. Young, and J. Mendelson III. 2019. Latency in problem solving as evidence for learning in varanid and helodermatid lizards, with comments on foraging techniques. Copeia 107: 78-84.
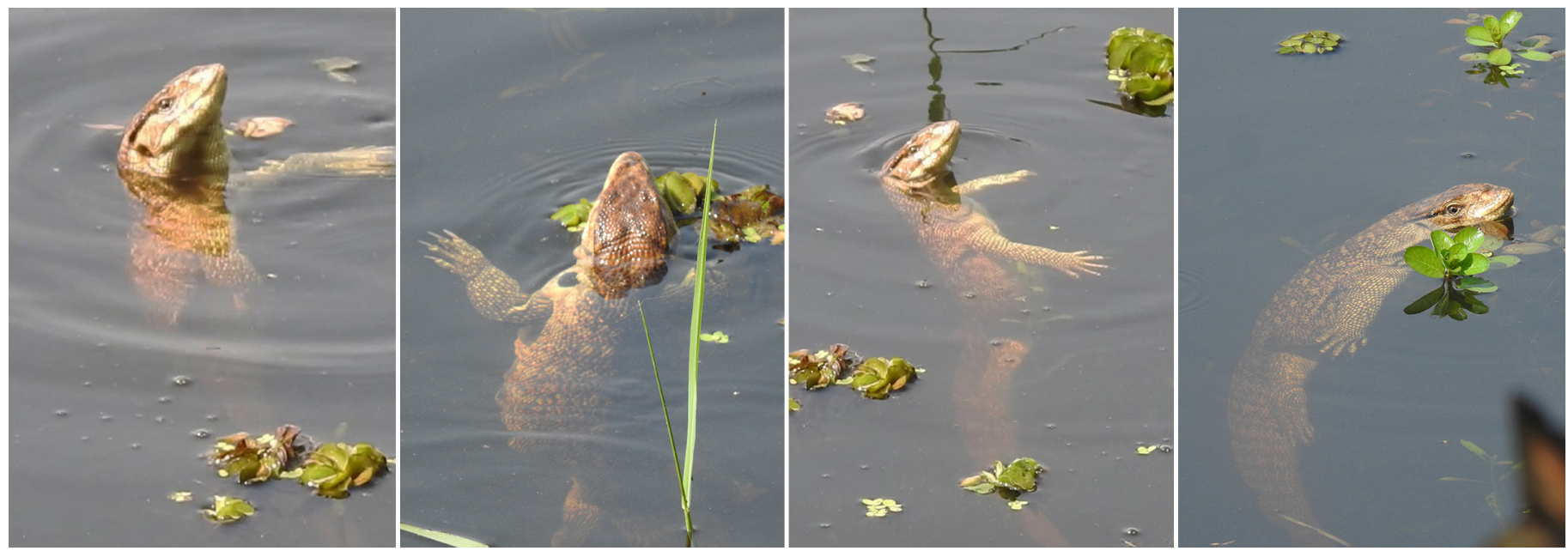

Fig. 1. Presumptive play behavior by a Yellow Monitor (Varanus flavescens) swimming in a vertical position while alternately moving forward and backward. 


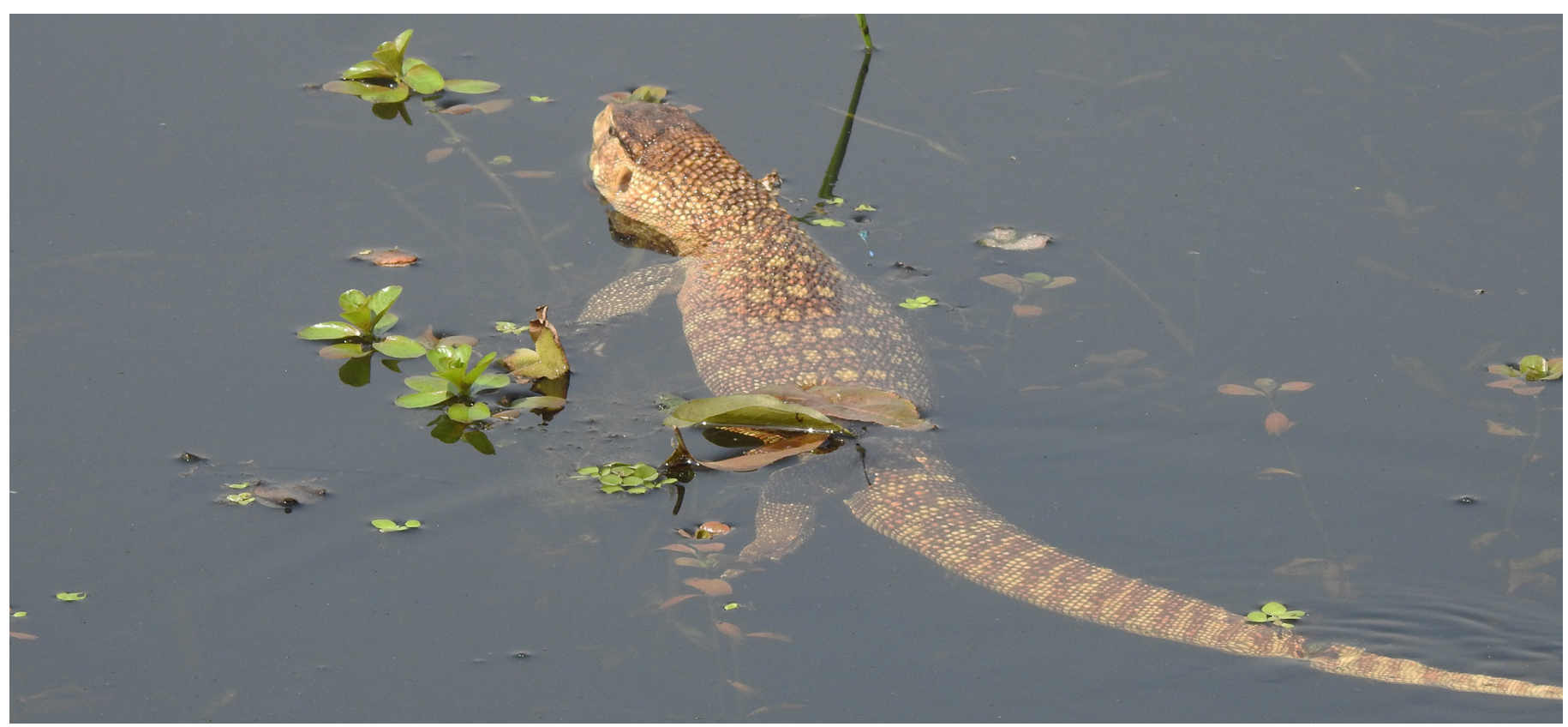

Fig. 2. A Yellow Monitor (Varanus flavescens) floating motionless on the surface between bouts of actively swimming in a vertical position.

Dinets, V. 2015. Play behavior in crocodilians. Animal Behavior and Cognition 2: 49-55.

Dryden, G., B. Green, D. King, and J. Losos. 1990. Water and energy turnover in a small monitor lizard, Varanus acanthurus. Wildlife Research 17: 641-646.

Gaalema, D.E. 2011. Visual discrimination and reversal learning in Rough-necked Monitor Lizards (Varanus rudicollis). Journal of Comparative Psychology 125: 246-249.

Hill, C. 1946. Playtime at the zoo. Zoo-Life 1: 24-26.

Iwaniuk, A.N., J.E. Nelson, and S.M. Pellis. 2001. Do big-brained animals play more? Comparative analyses of play and relative brain size in mammals. Journal of Comparative Psychology 115: 29-41.

Kane, D., A.C. Davis, and C.J. Michaels. 2019. Play behaviour by captive tree monitors, Varanus macraei and Varanus prasinus. Herpetological Bulletin 149: $28-31$.
Kramer, M. and G.M. Burghardt. 1998. Precocious courtship and play in emydid turtles. Ethology 104: 38-56.

Lazell, J.D. and N.C. Spitzer. 1977. Apparent play behavior in an American Alligator. Copeia 1977: 188.

Manrod, J.D., R. Hartdegen, and G.M. Burghardt. 2008. Rapid solving of a problem apparatus by juvenile Black-throated Monitor Lizards (Varanus albigularis albigularis). Animal Cognition 11: 267-273.

Mendyk, R.W. and H.G. Horn. 2011. Skilled forelimb movements and extractive foraging in the arboreal monitor lizard Varanus beccarii (Doria, 1874). Herpetological Review 42: 343-349.

Pontzer, H., D.A. Raichlen, A.D. Gordon, K.K. Schroepfer-Walker, M.C. Hare, M.F. O'Neill, K.M. Muldoon, H.M. Dunsworth, B.M. Wood, K. Isler, J. Burkart, M. Irwin, R.W. Shumaker, E.W. Lonsdorf, and S.R. Ross. 2014. Primate energy expenditure and life history. Proceedings of the National Academy of Sciences of the United States of America 111: 1433-1437. 